\title{
Las personas más destacadas en la cobertura periodística de la Marca España
}

\section{The most prominent people in the journalistic coverage of Marca España}

\section{As pessoas mais importantes na cobertura jornalística da Marca España}

\author{
Fernando Carcavilla ${ }^{1}$ \\ Universidad San Jorge (España) \\ fcarcavilla@usj.es \\ Ricardo Zugasti ${ }^{2}$ \\ Universidad de Zaragoza (España) \\ rzugasti@unizar.es
}

Fecha de recepción: 02 de marzo de 2020

Fecha de recepción evaluador: 03 de marzo de 2020

Fecha de recepción corrección: 20 de marzo de 2020

\footnotetext{
1 Fernando Carcavilla. Profesor de Publicidad y Relaciones Públicas en la Universidad San Jorge. Licenciado en Publicidad y Relaciones Públicas y Doctor en Comunicación por la Universidad San Jorge. Pertenece al grupo de investigación "Comunicación, Periodismo, Política y Ciudadanía", reconocido por el Gobierno de Aragón. ORCID: https://orcid.org/0000-0003-3786-4438

2 Ricardo Zugasti. Profesor de Periodismo en la Universidad de Zaragoza. Licenciado en Periodismo y Doctor en Comunicación por la Universidad de Navarra. Acreditado por ANECA como Profesor Titular de Universidad, tiene asimismo reconocido un sexenio de investigación por CNEAI. Ha sido Visiting Research Fellow en la Universidad de Sheffield (Reino Unido) y profesor visitante en diversas universidades extranjeras. Pertenece al grupo de investigación "Comunicación, Periodismo, Política y Ciudadanía", reconocido por el Gobierno de Aragón. ORCID: http://orcid.org/0000-0002-8558-9605
} 


\title{
Resumen
}

La creación de Marca España en junio de 2012 pone de manifiesto la preocupación del Gobierno español por mejorar la imagen de la nación tanto en el interior como en el exterior. Ciertas personas destacadas adquieren una especial relevancia en la construcción de la imagen de un país (Anholt, 2009a; Peralba, 2010). El presente artículo describe las características de la cobertura periodística del término 'marca España' en relación con determinadas personas entre los años 2012 y 2015, un periodo caracterizado por un contexto de crisis económica, social e institucional. Se analizan todas las piezas que incluyan la expresión 'marca España' mediante un análisis de contenido y se toman como muestra los tres diarios españoles con mayor difusión, El País, El Mundo y La Vanguardia. El trabajo demuestra que existe un estrecho vínculo periodístico entre la marca España y la Corona, el presidente del Gobierno y personalidades pertenecientes a la clase política y empresarial y al ámbito del deporte y la cultura.

Palabras clave: Prensa; identidad nacional; marca España; marca país; análisis de contenido

\begin{abstract}
The launching of Marca España in June 2012 reveals the Spanish Government concern to improve the country image both abroad and within the national territory. Some relevant people have a key role in the construction of the country image (Anholt, 2009a, Peralba, 2010). This article describes the features of the journalistic coverage of the term 'marca España' linked to specific people between 2012 and 2015, a period defined by a context of economic, social and institutional crisis. All the pieces that include the expression 'marca España' are analyzed through a content analysis and the three Spanish newspapers with the widest distribution, El País, El Mundo and La Vanguardia, are taken as a sample. This paper shows the close journalistic link between marca España and the Crown, the President of the Government and personalities of the political and business class as well as sport and culture.
\end{abstract}

Keywords: Press; national identity; marca España; nation brand; content analysis

\section{Resumo}

O lançamento da Marca España em junho de 2012 revela a preocupação do governo espanhol em melhorar a imagem do país no exterior e no território nacional. Algumas pessoas relevantes têm um papel fundamental na construção da imagem do país (Anholt, 2009a, Peralba, 2010). Este artigo descreve as características da cobertura jornalística do termo 'marca España' vinculada a pessoas específicas entre 2012 e 2015, período definido por um contexto de crise econômica, social e institucional. Todas as peças que incluem a expressão 'marca España' são analisadas por meio de uma análise de conteúdo e os três jornais espanhóis de maior distribuição El País, El Mundo e La Vanguardia são tomados como amostra. Este artigo mostra o estreito vínculo jornalístico entre a marca España e a 
Crown, o Presidente do Governo e as personalidades da classe política e empresarial, bem como o esporte e a cultura.

Palavras-chave: Press; identidade nacional; marca España; marca nacional; análise de conteúdo

\section{Introducción}

En junio de 2012, el Gobierno español crea la figura del Alto Comisionado para la Marca España. Esta iniciativa pretende mejorar la imagen del país en un escenario adverso caracterizado por la crisis económica e institucional, la corrupción política y el auge del independentismo en Cataluña.

Según indica el Ministerio de Exteriores,

"Marca España es una estrategia de gestión consciente de la imagen y reputación de España. Es una política de Estado cuya eficacia reside en el largo plazo. Su objetivo es mejorar la imagen de nuestro país, tanto en el interior como más allá de nuestras fronteras" (Ministerio de Asuntos Exteriores y Cooperación, 2016).

Uno de los principales canales para la construcción de la imagen exterior de un país lo constituyen las personas, especialmente aquellas que han alcanzado un prestigio internacional por destacar en un determinado ámbito (Anholt, 2009a; Peralba, 2010). Algunas de estas personas adquieren una dimensión simbólica al encarnar ciertos rasgos o atributos que refuerzan o atenúan percepciones asociadas a su país de origen.

Desde una perspectiva interna, estos referentes pueden influir en el sentimiento colectivo de identidad nacional al simbolizar determinados valores compartidos por la población. El concepto de identidad nacional se asienta en la conciencia de pertenecer a una comunidad adscrita a un territorio y compartir una serie de atributos perdurables y distintivos con los que la población se identifica y se diferencia de otras naciones (Capriotti, 2009; Guibernau, 2009). No obstante, esto no significa que esos atributos estén siempre asociados a valores positivos. El sentimiento de identidad nacional también puede incorporar atributos negativos si estos coinciden con la autopercepción de la población.

Por otra parte, la información periodística tiene un poder simbólico para definir la realidad y moldear los significados en la sociedad actual (Casero, 2009). En el caso que nos ocupa, la prensa diaria española contribuye a la construcción simbólica del significado de la marca España mediante las asociaciones que establece entre dicho concepto y determinadas personas.

El objetivo general de este trabajo es identificar esos vínculos y describir ciertas peculiaridades de la cobertura periodística. El estudio de este caso es tan solo una 
perspectiva concreta que nos permite adentrarnos en la comprensión de un fenómeno complejo y poliédrico como es la marca país.

El presente artículo se divide en cuatro partes. En la primera, se desarrolla el marco referencial de la investigación. En la segunda, se exponen los objetivos e hipótesis y se explica la técnica empleada. En la tercera, se muestran los resultados de la investigación sobre la cobertura periodística del concepto 'marca España' en relación con las personas. Finalmente, se ofrecen las conclusiones y se contemplan futuras vías de investigación.

\section{Marco referencial}

\section{Aproximación a la marca país}

La marca España es una concreción de la marca país o nation brand, un concepto acuñado por Simon Anholt en 1998 que hace referencia a la gestión estratégica de la reputación de los países (Olins, 2005; Anholt, 2009a).

Una década después, Anholt (2009b) señala que la imagen exterior de los países se basa en estereotipos muy arraigados y no puede cambiarse únicamente mediante estrategias de branding. Dicho autor afirma que las personas no tienen tiempo para conocer en profundidad la realidad de otros lugares y, en consecuencia, su percepción y sus conductas se ven afectadas por una serie de estereotipos (Anholt, 2009a). Guibernau (2009) indica que la creación de estereotipos supone una selección, y a menudo una exageración, de ciertos rasgos distintivos de los habitantes de un lugar.

A pesar de tratarse de percepciones simplificadas, Lippmann considera que los estereotipos son necesarios para ordenar la complejidad de la realidad y ubicarnos en la sociedad. En su obra clásica Public Opinion, el autor reconoce que no son una imagen completa del mundo, pero son la imagen de un mundo predecible en el que nos sentimos adaptados. Así, cualquier alteración de estos supone "un ataque a los cimientos de nuestro universo" (Lippmann, 2007, p. 93).

Según Anholt, los estereotipos se basan en la ignorancia y el prejuicio más que en la realidad y la experiencia, y suelen ser injustos. Sin embargo, considera que el hecho de que la reputación pertenezca a la esfera de las percepciones más que a la de la realidad no implica que no deba ser tenida en cuenta, ya que las percepciones determinan la conducta de las personas tanto o más que la realidad (2009a).

Anholt considera que la interacción de los países con el exterior se realiza a través de seis canales principales que configuran su modelo de 'identidad competitiva'. El autor propone trazar un plan concertado entre los principales agentes públicos y privados del país para coordinar sus acciones y sus mensajes y lograr una imagen más amplia y positiva (2009b).

A continuación, se describen las seis áreas de actividad que integran el modelo de Anholt representado en la figura 1 . 
1. La exportación de productos: las marcas con éxito y presencia internacional actúan como embajadoras de su país de origen al establecer una asociación positiva entre el país y la categoría a la que pertenecen (Olins, 2005). Esto facilita la internacionalización de otras empresas que se benefician del prestigio de la imagen país (Foro de Marcas Renombradas Españolas, 2016).

2. Cultura: hace referencia al atractivo de la cultura del país y al consumo de sus productos culturales en el exterior, así como a su presencia deportiva internacional. Varios autores definen este tipo de actividades como diplomacia cultural (La Porte, 2006; Manfredi, 2011; Azpíroz 2012).

3. Turismo: el branding de destino se asocia a la promoción turística de un país y es una de sus caras más visibles. A menudo, la estancia en un país implica un cambio en la percepción de los visitantes, quienes abandonan ciertos prejuicios y se convierten en prescriptores en su país de origen (Anholt, 2009b).

4. Gobierno y política: se refiere al reconocimiento y legitimidad internacional del gobierno e instituciones de un país y el atractivo de sus políticas, tanto exteriores como domésticas. Esta dimensión se vincula a la diplomacia pública y al poder blando [1] de un país.

5. Atracción de inversiones y talento: la competitividad de un país se manifiesta en su capacidad para atraer inversores y empresas extranjeras y para captar trabajadores cualificados, investigadores y estudiantes.

6. Personas: esta dimensión contempla la influencia que ejercen las personalidades destacadas y la población local en la construcción de la imagen país. Al tratarse del eje vertebrador de este trabajo, lo desarrollamos en mayor profundidad a continuación.

Figura 1: Canales básicos de la 'identidad competitiva'

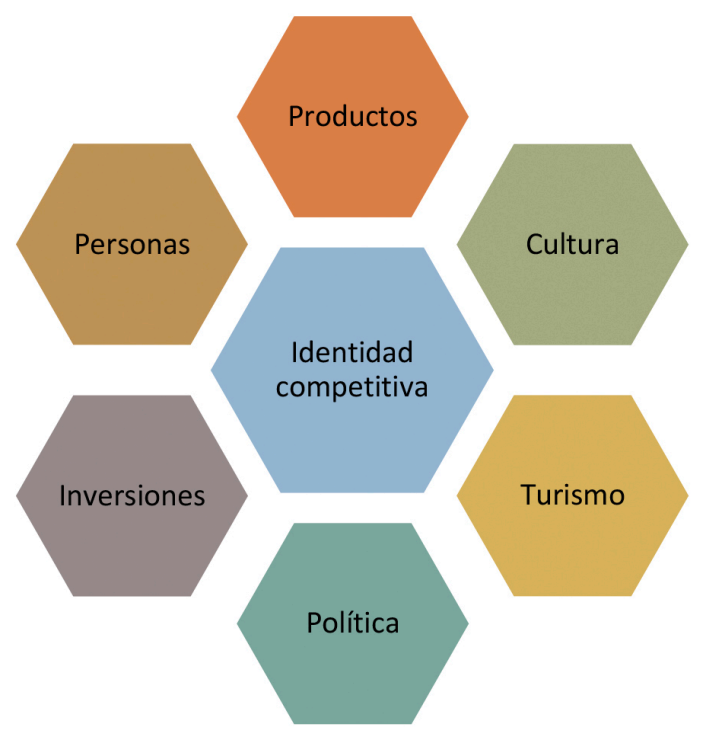

Fuente: elaboración propia. Adaptado de Anholt (2009a, 209). 


\section{La influencia de las personas en la imagen de un país}

La imagen de un país se configura en buena medida a través de la conducta y presencia internacional de personas destacadas en distintos ámbitos y de la ciudadanía en general. Personalidades de prestigio en distintas áreas como el espectáculo, el deporte, la cultura y la gastronomía pueden desempeñar una importante tarea de difusión de mensajes positivos y comunicar una serie de valores asociados a la marca país (Sánchez Guitián, 2012). El autor señala que la repercusión de estos referentes es un atractivo que debe aprovecharse para generar publicity [2], tanto de forma espontánea como a través de una estrategia planificada. Peralba (2010) también hace referencia a las personalidades destacadas en diversos campos y la influencia que ejercen sobre otras personas que las identifican con su país de origen. Además, indica que esto les exige asumir una responsabilidad como embajadores de la marca país.

En ese sentido, el Foro de Marcas Renombradas Españolas acredita anualmente a los Embajadores Honorarios de la Marca España, una iniciativa que tiene por objeto "ofrecer un reconocimiento público a las personas, físicas o jurídicas, de nacionalidad española, que a juicio del FMRE hayan contribuido significativamente a la generación y al fortalecimiento de una imagen positiva de España en el exterior" (Foro de Marcas Renombradas Españolas, 2019).

Una de las claves para la comprensión y diferenciación de una marca es el desarrollo de una personalidad de marca. Según Aaker, es una de las perspectivas a partir de las cuales construir una identidad de marca con mayor riqueza y profundidad. El autor la define como "un conjunto de características humanas asociadas con una marca determinada" (1996, p. 151). Aaker (1996) establece una relación entre la personalidad de una marca y las características percibidas de los habitantes de su país de origen. Por ejemplo, la marca Audi puede apropiarse de atributos como la precisión y la seriedad, comúnmente asociados a los alemanes. El desarrollo de la personalidad de marca favorece la comprensión de los públicos al representar beneficios y atributos del producto de forma eficaz. Además, contribuye a la diferenciación y guía las acciones de comunicación (Aaker, 1996).

Una de las formas de construir una personalidad de marca es, precisamente, asociándola a personajes reales o ficticios, de modo que transmitan sus valores de una forma mucho más verosímil (De Toro, 2009).

Podemos concluir que la asociación de un país con determinadas personas implica una transferencia de los atributos y los valores que estas representan a la propia imagen del país.

La población en su conjunto también es considerada como un factor de influencia en la construcción de la imagen país (Anholt, 2009a; Peralba, 2010). Su comportamiento, tanto en el extranjero como al tratar a los visitantes, influye en las percepciones (Anholt, 2009a). En ese sentido, Sheinfeld señala la importancia de las migraciones y el gran potencial que tiene la interacción con las diásporas como herramienta de diplomacia 
pública. La citada autora considera que las principales ventajas de la 'diplomacia pública de diáspora' son lograr credibilidad en el país anfitrión y entre sus ciudadanos, el conocimiento y expansión del idioma, la cultura y las tradiciones y la familiaridad con los medios, políticos y actores más importantes (2012).

\section{Metodología}

\section{Objetivos}

A raíz de lo expuesto anteriormente, consideramos que la población local y, en particular, sus figuras más destacadas desarrollan una labor esencial en la configuración de la imagen de un país.

En consecuencia, queremos conocer qué características tiene la cobertura periodística del término 'marca España' [3] en relación con las personas. Concretamente, planteamos los siguientes objetivos específicos:

1. Conocer en qué medida se vincula el término 'marca España' con determinadas personas o grupos de personas en la prensa diaria española.

2. Detectar si el hecho noticioso es valorado de forma positiva o negativa con relación a su influencia sobre la marca España.

3. Concretar con qué personalidades concretas pertenecientes a distintos ámbitos se relaciona el concepto marca España.

4. Definir los rasgos de la cobertura informativa realizada por cada uno de los diarios analizados, detectando similitudes y diferencias entre ellos.

\section{Hipótesis}

A partir de los anteriores objetivos, planteamos las siguientes hipótesis en nuestra investigación:

H1. El vínculo establecido por la prensa entre la marca España y las personas es muy estrecho, dado que la mayor parte de los hechos noticiosos son protagonizados por determinadas personas o colectivos de personas.

H2. La valoración del impacto de los hechos noticiosos sobre la marca España es predominantemente negativa por el contexto sociopolítico adverso.

H3. El Rey y el presidente del Gobierno tienen un protagonismo destacado en la cobertura como máximos representantes de la nación. Además, otras personalidades con prestigio internacional en los ámbitos del deporte y la cultura también tienen una presencia relevante (Anholt, 2009a; Peralba, 2010). 
H4. Los diarios analizados conceden diferente importancia a determinadas personas y hechos vinculados a la marca España y presentan peculiaridades al valorarlos.

\section{Técnica}

La técnica escogida para analizar la cobertura periodística es el análisis de contenido cuantitativo, una técnica que permite la "descripción objetiva, sistemática y cuantitativa del contenido manifiesto de la comunicación” (Berelson, 1952, p. 18) y cuyo fin es medir unas variables concretas (Kerlinger, 1986). Sierra Bravo (1997) afirma que esta técnica es la más elaborada y prestigiosa en el campo de la observación documental. El análisis de contenido cuantitativo consiste en medir con qué frecuencia aparecen una serie de rasgos en un contenido. Para ello, es necesario delimitar previamente el objeto de estudio, el diseño de la muestra, la franja temporal y la unidad de análisis con la que se trabajará (Zurutuza, 2012).

El código de análisis utilizado es original y se compone de quince variables con sus respectivos valores asociados, según se muestra en la tabla 1. El código contempla las principales categorías de personas según el ámbito al que pertenecen.

Tras el proceso de codificación, se ha realizado el tratamiento estadístico de los datos con el programa SPSS para posteriormente presentarlos en el apartado de Resultados como gráficos y tablas de frecuencias.

Tabla 1: Código de análisis de contenido

\begin{tabular}{|c|c|c|}
\hline \multicolumn{2}{|c|}{ Variable } & \multirow{2}{*}{$\begin{array}{l}\text { Valores asociados } \\
\text { 1. El País } \\
\text { 2. El Mundo } \\
\text { 3. La Vanguardia }\end{array}$} \\
\hline 1 & Diario al que pertenece la unidad de análisis. & \\
\hline 2 & $\begin{array}{l}\text { ¿Se vincula la marca España a determinadas } \\
\text { personas o grupos de personas? }\end{array}$ & $\begin{array}{l}\text { 1. Sí } \\
\text { 2. No }\end{array}$ \\
\hline 3 & $\begin{array}{l}\text { En caso de respuesta afirmativa en la variable } \\
2 \text {, ¿cómo valora la unidad de análisis la } \\
\text { influencia del hecho noticioso sobre la marca } \\
\text { España? }\end{array}$ & $\begin{array}{l}\text { 1. Positiva } \\
\text { 2. Negativa }\end{array}$ \\
\hline 4 & $\begin{array}{l}\text { En caso de respuesta afirmativa en la variable } \\
2 \text {, ¿se vincula a algún miembro de la Casa } \\
\text { Real? }\end{array}$ & $\begin{array}{l}\text { 1. Juan Carlos de Borbón } \\
\text { 2. Sofía de Grecia } \\
\text { 3. Felipe de Borbón } \\
\text { 4. Letizia Ortiz } \\
\text { 5. Elena de Borbón } \\
\text { 6. Cristina de Borbón } \\
\text { 7. Otros miembros de la Casa Real } \\
\text { 8. Se vincula a varios de los anteriores } \\
\text { 9. No }\end{array}$ \\
\hline 5 & $\begin{array}{l}\text { En caso de respuesta afirmativa en la variable } \\
2 \text {, ¿se vincula al presidente del Gobierno de }\end{array}$ & $\begin{array}{l}\text { 1. Sí } \\
\text { 2. No }\end{array}$ \\
\hline
\end{tabular}




\begin{tabular}{|c|c|c|}
\hline & España? & \\
\hline 6 & $\begin{array}{l}\text { En caso de respuesta afirmativa en la variable } \\
2, \text { ise vincula al ministro de Asuntos } \\
\text { Exteriores? }\end{array}$ & $\begin{array}{l}\text { 1. Sí } \\
\text { 2. No }\end{array}$ \\
\hline 7 & $\begin{array}{l}\text { En caso de respuesta afirmativa en la variable } \\
\text { 2, ¿se vincula a otros miembros concretos del } \\
\text { Gobierno de España? }\end{array}$ & $\begin{array}{l}\text { 1. Sí } \\
\text { 2. No }\end{array}$ \\
\hline 8 & $\begin{array}{l}\text { En caso de respuesta afirmativa en la variable } \\
2, \text { ¿se vincula a políticos concretos no } \\
\text { miembros del Gobierno de España? }\end{array}$ & $\begin{array}{l}\text { 1. Sí } \\
\text { 2. No }\end{array}$ \\
\hline 9 & $\begin{array}{l}\text { En caso de respuesta afirmativa en la variable } \\
2, \quad \text { ise vincula al Alto Comisionado del } \\
\text { Gobierno para la Marca España? }\end{array}$ & $\begin{array}{l}\text { 1. Sí } \\
\text { 2. No }\end{array}$ \\
\hline 10 & $\begin{array}{l}\text { En caso de respuesta afirmativa en la variable } \\
\text { 2, ¿se vincula a personalidades concretas de } \\
\text { alguno de los siguientes ámbitos culturales? }\end{array}$ & $\begin{array}{l}\text { 1. Arquitectura } \\
\text { 2. Artes plásticas } \\
\text { 3. Cine } \\
\text { 4. Deportes } \\
\text { 5. Gastronomía } \\
\text { 6. Literatura y teatro } \\
\text { 7. Medios de comunicación } \\
\text { 8. Moda y alta costura } \\
\text { 9. Música } \\
\text { 10. Toros } \\
\text { 11. Otros } \\
\text { 12. Varios de los anteriores } \\
\text { 13. No }\end{array}$ \\
\hline 11 & $\begin{array}{l}\text { En caso de respuesta afirmativa en la variable } \\
38, \text { ¿se vincula a empresarios concretos? }\end{array}$ & $\begin{array}{l}\text { 1. Sí } \\
\text { 2. No }\end{array}$ \\
\hline 12 & $\begin{array}{l}\text { En caso de respuesta afirmativa en la variable } \\
38, \text { ¿se vincula a científicos concretos? }\end{array}$ & $\begin{array}{l}\text { 1. Sí } \\
\text { 2. No }\end{array}$ \\
\hline 13 & $\begin{array}{l}\text { En caso de respuesta afirmativa en la variable } \\
38 \text {, ¿se vincula a misioneros, miembros de } \\
\text { ONG, y/o voluntarios concretos? }\end{array}$ & $\begin{array}{l}\text { 1. Sí } \\
\text { 2. No }\end{array}$ \\
\hline 14 & $\begin{array}{l}\text { En caso de respuesta afirmativa en la variable } \\
38 \text {, ¿se vincula a la población española en } \\
\text { general o a algún sector de la ciudadanía en } \\
\text { particular? }\end{array}$ & $\begin{array}{l}\text { 1. Sí } \\
\text { 2. No }\end{array}$ \\
\hline 15 & $\begin{array}{l}\text { En caso de respuesta afirmativa en la variable } \\
\text { 38, ¿se vincula a los emigrantes españoles? }\end{array}$ & $\begin{array}{l}\text { 1. Sí } \\
\text { 2. No }\end{array}$ \\
\hline
\end{tabular}

Fuente: elaboración propia 


\section{Diseño de la muestra}

El objeto de estudio de la investigación es el tratamiento periodístico que el concepto 'marca España' ha recibido en la prensa diaria española en relación con las personas. Para realizar el análisis, hemos escogido una muestra de fuentes hemerográficas a partir de unos criterios de selección temporales, de difusión y de pluralidad.

El criterio temporal establece un periodo que comienza en junio de 2012, mes en el que se creó la figura del Alto Comisionado del Gobierno para la Marca España, y termina en diciembre de 2015, coincidiendo con las elecciones generales que marcaron el fin de la legislatura del Gobierno responsable del proyecto Marca España.

El segundo criterio de selección ha sido la difusión diaria en el año 2013. Según los datos obtenidos de OJD (2017), las ediciones impresas de El País, El Mundo y La Vanguardia alcanzaron los mayores promedios de difusión entre la prensa diaria generalista en el año 2013.

Respecto al criterio de pluralidad política, periodística y territorial, El País y El Mundo son los dos principales diarios generalistas editados en Madrid cuyo enfoque sobre diversas cuestiones ha sido tradicionalmente divergente. La Vanguardia es el principal diario editado en Cataluña y su presencia en nuestro estudio aporta un especial interés por el auge del independentismo catalán que hemos señalado anteriormente.

Hemos definido como unidades codificables todas aquellas piezas pertenecientes a cualquier género periodístico que incluyan literalmente el término 'marca España' ubicadas en la edición básica de los tres diarios. Tras consultar las hemerotecas en línea, se han obtenido 936 unidades codificables: 359 de El País, 386 de El Mundo y 191 de La Vanguardia.

\section{Resultados}

\section{Descripción general de la cobertura}

El 78,8\% de las unidades de análisis vinculan la marca España con determinadas personas o grupos de personas, según observamos en el gráfico 1. Si bien se trata de un porcentaje muy elevado, resulta previsible dado que la mayor parte de las informaciones hacen referencia a personas concretas vinculadas a los hechos. Además, observamos que el 55,6\% de las informaciones publicadas ofrecen una visión positiva o neutra de la influencia del hecho noticioso sobre la marca España. 
Gráfico 1: Vinculación del concepto 'marca España' con el área de personas o grupos de personas y valoración de la influencia del hecho noticioso sobre la marca España (en porcentaje).

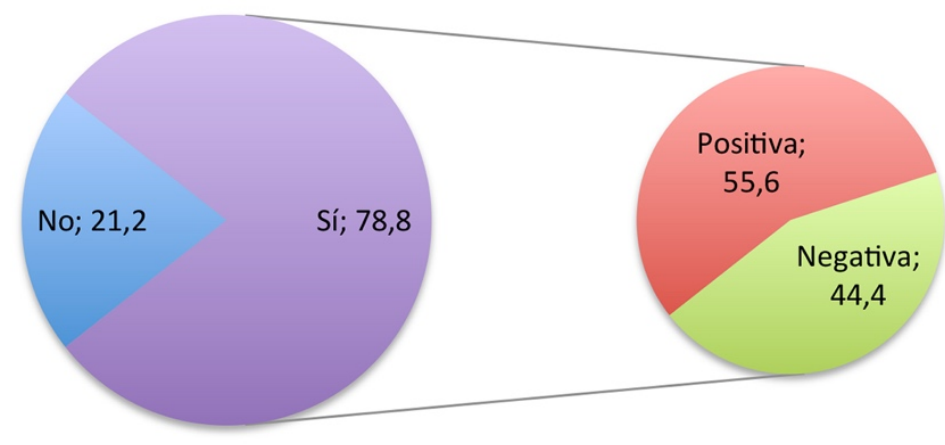

Fuente: elaboración propia.

E1 26,6\% de las informaciones que hacen referencia a personas vincula la marca España con algún miembro de la Casa Real. Conviene señalar que en nuestro análisis hacemos referencia a la persona y no al cargo, puesto que durante el periodo analizado se produjo la abdicación del Rey Don Juan Carlos de Borbón en favor de su hijo Don Felipe, quien fue proclamado Rey el 19 de junio de 2014. Sobre ambas figuras recae el protagonismo en la cobertura, obteniendo el primero un $11,2 \%$ y un $6,1 \%$ el segundo.

Dos años antes, en abril de 2012, el Rey se fracturó la cadera en una cacería en Botsuana y tuvo que ser intervenido de urgencia en España. Este suceso desató la polémica al coincidir con uno de los momentos más duros de la crisis económica, provocando la indignación de la opinión pública ante la imagen de irresponsabilidad de Don Juan Carlos. La gravedad de la situación hizo que el Rey se disculpase públicamente al abandonar el hospital, un gesto inédito en la reciente historia de España. Aun así, el descenso de la popularidad del Monarca y de la institución que representa obligó a su entorno a tomar algunas medidas. Según un reportaje de El Mundo,

"a instancias del Rey, Zarzuela diseñó un plan: el Monarca se convirtió en la cara de la Marca España con una serie de viajes de trabajo exprés, sin la Reina y con empresarios. El objetivo era mejorar la imagen exterior de un país económicamente quebrado y, de paso, recordar a los ciudadanos la valía de Don Juan Carlos" (Romero, 14 de abril de 2013, p. 7).

Así, en junio de 2012, el Rey viajó a Brasil y Chile, en julio del mismo año a Rusia y en octubre a la India. Una información publicada en El País a raíz de este último viaje, lo califica como un despliegue de diplomacia económica para intentar abrir camino a las empresas españolas, como podemos observar en la figura 2. En dicha noticia se explica que el Rey fue acompañado por el ministro de Asuntos Exteriores, José Manuel García-Margallo; el de Industria, Energía y Turismo, José Manuel Soria; el de Defensa, Pedro Morenés; y la de Fomento, Ana Pastor, junto al secretario de Estado de Comercio, Jaime García-Legaz. Además, los acompañó el presidente de la patronal CEOE, Arturo 
Fernández, el presidente del Consejo Superior de Cámaras de Comercio, Manuel Teruel, y 12 empresarios de compañías como Sacyr, Navantia, OHL, Abengoa, Acciona, Indra, Talgo, Caf o Roca, con la intención de obtener contratos (Junquera, 25 de octubre de 2012, p. 24). La representación institucional y empresarial en el resto de las acciones de diplomacia económica encabezadas por el Rey fue similar a la descrita y no es extraño encontrar informaciones en las que se califica al Monarca como "primer embajador de España” (Andreu, 12 de julio de 2014, p. 33).

Figura 2: Titular de una noticia relativa a una de las acciones de diplomacia económica del Rey Juan Carlos.

\section{El Rey viaja a India para vender la marca España a 1.280 millones de consumidores}

Cuatro ministros tratan de vencer el recelo a la inversión extranjera en ese país

Fuente: Junquera, 25 de octubre de 2012: 24.

La Infanta Cristina también alcanza cierto protagonismo $(2,4 \%)$ al ser imputada en abril de 2013 por delito fiscal en el caso Nóos, un escándalo de corrupción protagonizado por su marido, Iñaki Urdangarin, que fue el detonante de la crisis institucional de la Monarquía en el año 2010.

La Reina Sofía $(1,8 \%)$ y Letizia Ortiz $(1,4 \%)$ aparecen en una posición más discreta, mientras que las referencias a otros miembros $(1,2 \%)$ o a varios de los anteriores $(2,4 \%)$ completan la cobertura de la Casa Real, como puede observarse en el gráfico 2

Gráfico 2: Vinculación del concepto 'marca España’ con algún miembro de la Casa Real (en porcentaje).

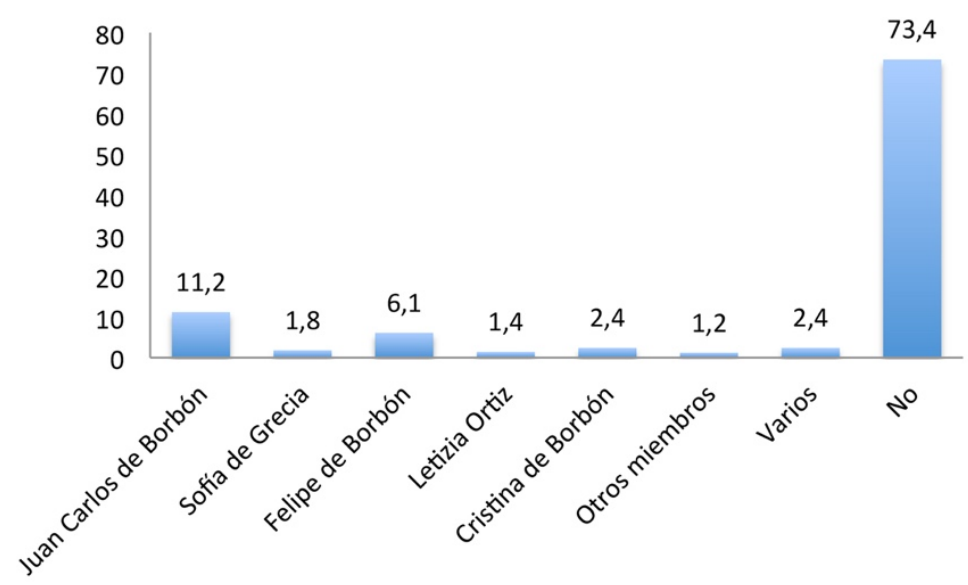

Fuente: elaboración propia.

Además de los miembros de la Casa Real, existen otras personas y colectivos que han recibido cobertura mediática en relación con la marca España, según se observa en la tabla 2. La figura que acapara el máximo protagonismo es la del presidente del Gobierno, Mariano Rajoy, con un 25,3\%. La segunda figura con mayor visibilidad es el Ministro de 
Asuntos Exteriores y de Cooperación, José Manuel García-Margallo, con un 17,1\%, hecho que no nos sorprende dada la naturaleza de su cargo, además de ser el mayor artífice de la iniciativa Marca España. La tercera persona destacada en orden de cobertura -sin contabilizar al Rey- es el Alto Comisionado para la Marca España, Carlos Espinosa de los Monteros, con un 9,1\%. Si bien se trata de la cara más visible del proyecto, comprobamos que mediáticamente queda algo eclipsado por la presencia del Ministro de Exteriores.

Otros políticos pertenecientes al Gobierno suman un $23 \%$ de la cobertura y el resto de los políticos mencionados no vinculados al Gobierno alcanzan el 21,4\%. Esto pone de manifiesto el elevado componente político de la marca España.

Las menciones a empresarios relacionados con la marca España obtienen una presencia muy destacada en la cobertura, alcanzando un 23,6\%. Sin embargo, el protagonismo de los científicos es muy discreto, con tan solo un 3,3\%. Los misioneros, voluntarios o miembros de ONG tampoco gozan de una buena visibilidad (1,9\%), al igual que los emigrantes españoles, con un 3,5\% de la cobertura. Por último, la población española en general obtiene un $8,8 \%$ de cobertura.

Tabla 2: Vinculación del concepto 'marca España' con personas o colectivos concretos (en porcentaje).

\begin{tabular}{|l|l|l|l|}
\hline Personas vinculadas & Sí & No & Total \\
\hline Miembros de la Casa Real & 26,6 & 73,4 & 100 \\
\hline Presidente del Gobierno & 25,3 & 74,7 & 100 \\
\hline Ministro de Asuntos Exteriores & 17,1 & 82,9 & 100 \\
\hline Otros miembros del Gobierno & 23 & 77 & 100 \\
\hline Políticos no miembros del Gobierno & 21,4 & 78,6 & 100 \\
\hline Alto Comisionado Marca España & 9,1 & 90,9 & 100 \\
\hline Personalidades de ámbitos culturales & 29,1 & 70,9 & 100 \\
\hline Empresarios & 23,6 & 76,4 & 100 \\
\hline Científicos & 3,3 & 96,7 & 100 \\
\hline Misioneros o miembros de ONG & 1,9 & 98,1 & 100 \\
\hline Población española & 8,8 & 91,2 & 100 \\
\hline Emigrantes españoles & 3,5 & 96,5 & 100 \\
\hline
\end{tabular}

Fuente: elaboración propia.

Las personalidades relacionadas con la cultura suman un $29,1 \%$, siendo este colectivo especialmente destacado en cuanto a la relación de personas con la marca España. Dada la variedad de ámbitos que integran este campo, vamos a desarrollarlo en mayor profundidad.

Como se observa en el gráfico 3, los deportistas son, con un 9,1\% de la cobertura, las personalidades más vinculadas a la marca España dentro del área de cultura. Este dato muestra el predominio del ámbito deportivo en el área de la cultura. Es habitual vincular los triunfos de los deportistas españoles internacionales con la marca España (Carcavilla y Zugasti, 2019a). Por ejemplo, en un editorial de El Mundo, cuyo titular se muestra en 
la figura 3, se ensalza la victoria del tenista español Rafael Nadal [4] en el torneo de Roland Garros en el año 2013:

"Tantas cosas están mal hoy en nuestro país que los triunfos de Nadal y del deporte español son una inyección de optimismo que se antoja imprescindible para alimentar la esperanza de que hay luz al final del túnel. Un triunfo como el de ayer en París hace más por la Marca España que todas las jornadas que los políticos puedan organizar a base de flamenco y jabugo" (10 de junio de 2013, p. 3).

Figura 3: Titular de un editorial relativo al triunfo de Rafael Nadal en Roland Garros en el año 2013.

\section{El mejor deportista español en el peor momento de España}

Fuente: El mejor deportista español en el peor momento de España, 10 de junio de 2013: 3.

Las personalidades pertenecientes a los demás ámbitos culturales registran una cobertura inferior. Observamos que, en varias ocasiones, se hace referencia a figuras consagradas en sus respectivas disciplinas, cuya obra forma parte del patrimonio cultural español. En un artículo de opinión publicado en El Mundo, la periodista Eva Díaz Pérez reflexiona sobre la nación y concluye que "tal vez eso sea España: una página de El Quijote, una pincelada de Picasso, un verso de Cernuda..." (Díaz Pérez, 23 de septiembre de 2015, p. 18).

El registro más elevado lo obtienen las personalidades asociadas a la literatura y el teatro $(3,7 \%)$. Sin embargo, detectamos que se trata de un colectivo que se suele mostrar crítico con la marca España. Por ejemplo, el escritor Juan Goytisolo, en una entrevista tras ganar el premio Cervantes 2014, afirma que uno de los grandes mitos de la España de hoy es "reducir España a la Marca España y no ver la cruda realidad de una sociedad que está sufriendo por el paro y la marginación. Este mito de la Marca España hay que deshacerlo" (Rodríguez Marcos, 25 de noviembre de 2014, p. 39).

La siguiente posición por orden de cobertura la comparten las figuras vinculadas a los medios de comunicación y a la música, alcanzando cada categoría un $3 \%$. Les suceden las personalidades pertenecientes al campo de las artes plásticas, cuya cobertura coincide con las de la moda y la alta costura $(2,6 \%)$. En relación con estas últimas, destacan varias informaciones referentes a la Mercedes-Benz Fashion Week de Madrid en las que se menciona a varios diseñadores españoles. En una crónica publicada en $E l$ Mundo, la autora critica la inasistencia de diversas personalidades a este evento, señalando que "no se nos puede llenar la boca con la Marca España, incluso crear organismos que la defienden, si al final despreciamos lo nuestro de una manera tan flagrante" (Aldaz, 19 de febrero de 2014, p. 45). Este es otro ejemplo de la tendencia a 
evidenciar las contradicciones entre el discurso oficial y determinados hechos o conductas.

Las personalidades del ámbito cinematográfico ocupan la siguiente posición $(1,9 \%)$. En este caso, destacamos las informaciones referentes al nombramiento Antonio Banderas como embajador de la Marca España. En una crónica de sociedad publicada en La Vanguardia, se destaca la presencia del actor en una recepción ofrecida a los príncipes de Asturias por el embajador de Estados Unidos en España, James Costos (Alcázar, 16 de noviembre de 2013, p. 9). Sin embargo, los actores y directores españoles suelen mostrarse críticos con la marca España. Por ejemplo, en una columna publicada en el diario El País, David Trueba reflexiona sobre la identidad nacional y señala que las películas de Torrente [5] representan un estado de ánimo reconocible por muchos. El director afirma que "Torrente es hoy un personaje referencial que nos permite identificar comportamientos, opiniones, pasiones y actitudes que identificamos con nuestra sociedad" y cita algunos ejemplos entre los que incluye el concepto 'marca España' (Trueba, 3 de octubre de 2014, p. 61).

Las figuras vinculadas a la gastronomía protagonizan el $1,2 \%$ de las informaciones, mientras que las relacionadas con la arquitectura representan el $0,8 \%$. Además, tan solo el 0,1\% de las informaciones vincula la marca España con figuras de la tauromaquia, hecho que llama la atención al tratarse de un tópico cultural muy arraigado.

\section{Gráfico 3: Vinculación del concepto 'marca España' con personalidades de distintos ámbitos} culturales (en porcentaje).

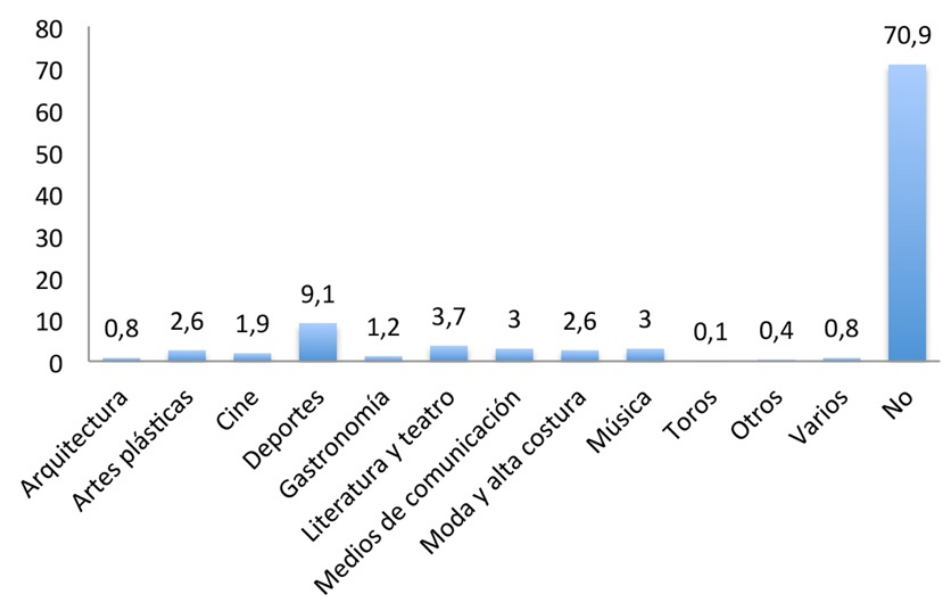

Fuente: elaboración propia.

\subsection{Vinculación de la marca España con las personas según periódico}

Para completar este apartado, vamos a analizar la vinculación del concepto 'marca España' con determinadas personas o grupos de personas según cada periódico. En la tabla 3 observamos de nuevo un equilibrio entre los tres diarios, situándose $L a$ Vanguardia en primer lugar (81,2\%), seguido por El Mundo (79,8\%) y El País (76,6\%). 
Tabla 3: Vinculación del concepto 'marca España' con el área de personas o grupos de personas según periódico (en porcentaje).

\begin{tabular}{|l|l|l|l|}
\hline $\begin{array}{l}\text { Vinculación con el área de } \\
\text { personas }\end{array}$ & El País & El Mundo & La Vanguardia \\
\hline Sí & 76,6 & 79,8 & 81,2 \\
\hline No & 23,4 & 20,2 & 18,8 \\
\hline Total & 100 & 100 & 100 \\
\hline
\end{tabular}

Fuente: elaboración propia.

La valoración de la influencia del hecho noticioso sobre la marca España varía en función del diario, con un predominio de valoraciones positivas en El Mundo (63,6\%), seguido por El País (53,8\%), frente a La Vanguardia (42,6\%), cuyo registro, observamos, es un $21 \%$ inferior a El Mundo.

A continuación, analizamos el protagonismo concedido por cada diario a los distintos individuos o colectivos vinculados a la marca España. La vinculación a miembros de la Casa Real registra una llamativa semejanza en El País $(29,8 \%)$ y El Mundo (29,5\%), aproximadamente el doble que en La Vanguardia (14,8\%). En concreto, Don Juan Carlos de Borbón obtiene una mayor presencia en El País (14,5\%), seguido por El Mundo (10,4\%) y La Vanguardia (7,1\%). Sin embargo, Doña Sofía registra una mayor presencia en El Mundo (2,9\%) respecto a El País (1,1\%) y La Vanguardia (0,6\%). Don Felipe de Borbón obtiene un protagonismo muy similar en El País (7,3\%) y El Mundo (7,1\%), notablemente superior al concedido por La Vanguardia (1,9\%). Por su parte, Doña Letizia Ortiz tiene una presencia equilibrada en El País (1,5\%), en El Mundo (1,3\%), y en La Vanguardia (1,3\%). La Infanta Doña Cristina de Borbón recibe una mayor atención por parte de El Mundo (2,9\%) y La Vanguardia $(2,6 \%)$ respecto a El País $(1,8 \%)$. Otros miembros de la Casa Real obtienen una mayor presencia en El Mundo $(2,3 \%)$ que en La Vanguardia (0,6\%) y El País (0,4\%). Por último, la vinculación a varios de los anteriores se da con mayor frecuencia en El País (3,3\%) y El Mundo (2,6\%) que en La Vanguardia $(0,6 \%)$.

La atención prestada al presidente del Gobierno, Mariano Rajoy, es superior en El País (28,7\%), seguido por La Vanguardia (26,5\%) y El Mundo (21,8\%). El ministro de Asuntos Exteriores, José Manuel García-Margallo, obtiene un mayor protagonismo en El Mundo (18,2\%), seguido por El País (16,7\%) y La Vanguardia (15,5\%). Otros miembros concretos del Gobierno de España reciben una mayor atención por parte de $E l$ Mundo (25,3\%), seguido de cerca por La Vanguardia (24,5\%) y El País (19,6\%). Con relación a otros políticos concretos no pertenecientes al Gobierno de España, observamos una frecuencia ligeramente superior en La Vanguardia (25,2\%) respecto a El País (20,7\%) y El Mundo (20,1\%).

La figura del Alto Comisionado del Gobierno para la Marca España obtiene un mayor protagonismo por parte La Vanguardia (12,3\%), seguido por El Mundo (11\%), y a una mayor distancia, por El País (5,1\%). 
La vinculación de la marca España con personalidades concretas de determinados ámbitos culturales es, en líneas generales, más frecuente en El País (32,7\%), seguido por La Vanguardia (28,4\%) y El Mundo (26,3\%). A continuación, vamos a desglosar estos porcentajes señalando los resultados más significativos.

Las personalidades del ámbito deportivo son las que reciben una mayor atención por parte de los tres diarios. Esto sucede especialmente en El Mundo (11\%), seguido por El País (9,1\%), mientras que en La Vanguardia es más infrecuente (5,2\%). Estas cifras contrastan con los resultados obtenidos en una investigación previa en los que La Vanguardia se muestra como el diario que, proporcionalmente, mayor relación establece entre deporte y marca España (38,2\%), seguido por El Mundo (33,9\%) y El País (30,7\%). Comprobamos, por tanto, que El Mundo y El País presentan una mayor tendencia a personalizar la marca España en los logros de los deportistas, mientras que La Vanguardia muestra una inclinación a establecer vínculos que trascienden lo deportivo (Carcavilla y Zugasti, 2019a).

Respecto a las personalidades representativas de las distintas disciplinas artísticas, destacan las pertenecientes a la literatura y el teatro en la cobertura de El País (6,2\%), seguido por La Vanguardia (3,9\%), mientras que su presencia en El Mundo es notablemente inferior $(1,3 \%)$.

Comprobamos que la mayor presencia de personalidades vinculadas al arte en el diario El País se manifiesta en varias disciplinas. Por ejemplo, en el cine, El País (3,3\%) obtiene un mayor porcentaje respecto a La Vanguardia (2,6\%) y El Mundo (0,3\%). En las artes plásticas, es de nuevo El País el que alcanza un mayor registro (4\%), seguido por La Vanguardia (2,6\%) y El Mundo (1,3\%). Este patrón se repite en la arquitectura, con un mayor protagonismo en El País (1,5\%), seguido por La Vanguardia (0,6\%) y El Mundo $(0,3 \%)$. La única excepción la encontramos en la música, cuyas figuras se vinculan a la marca España con más frecuencia en El Mundo (3,6\%) que en La Vanguardia (2,6\%) y El País (2,5\%).

Con relación a otras áreas de la cultura, las personalidades del ámbito de la gastronomía reciben más atención por parte de El Mundo (1,6\%), seguido por La Vanguardia (1,3\%) y El País $(0,7 \%)$. Las figuras vinculadas a los medios de comunicación tienen mayor presencia en La Vanguardia (5,2\%), seguido de El Mundo (2,6\%) y El País (2,2\%). La atención prestada a las personalidades de la moda y la alta costura por parte de El Mundo (2,6\%), La Vanguardia (2,6\%) y El País (2,5\%) es muy homogénea. Los vínculos establecidos entre figuras del mundo del toro y la marca España son prácticamente nulos, en El Mundo (0,3\%) y no registran resultados en El País y La Vanguardia.

La presencia de personalidades de otras áreas culturales diferentes a las anteriores también es muy escasa en La Vanguardia (1,3\%), El País (0,4\%), y El Mundo (0\%). Por último, el vínculo de la marca España con personalidades de varios de los anteriores ámbitos es mínima tanto en El Mundo (1,3\%), La Vanguardia (0,6\%) y El País (0,4\%). 
A continuación, vamos a analizar la vinculación de la marca España con personas concretas pertenecientes a otros campos. Las figuras del mundo empresarial obtienen un destacado protagonismo en los tres diarios, especialmente en El Mundo (28,2\%), seguido por La Vanguardia (20,6\%) y El País (20\%). Según comprobamos en una investigación previa, El Mundo es el diario que más veces vincula el concepto 'marca España' con el área de empresas y productos españoles (56,2\%), frente a El País (50,4\%) y La Vanguardia (44,5\%) (Carcavilla y Zugasti, 2019b). Estos datos ponen de manifiesto la mayor importancia concedida por El Mundo al ámbito empresarial en relación con la marca España.

En cambio, las referencias a científicos concretos relacionados con la marca España son escasas en los tres diarios, según observamos en La Vanguardia (3,9\%), El Mundo (3,2\%) y El País (2,9\%). Los misioneros, voluntarios y miembros de ONG concretos también tienen un protagonismo bastante limitado, aunque son más destacados en El Mundo (2,9\%) que en La Vanguardia (1,3\%) y El País (1,1\%). El diario que más atención presta a los emigrantes españoles es El País (5,1\%), seguido por La Vanguardia (3,9\%) y El Mundo (1,9\%).

Por último, la población española en su conjunto o algún sector concreto de la ciudadanía reciben mayor atención por parte de La Vanguardia (11\%), seguido por El Mundo (8,4\%) y El País (8\%).

\section{Discusión y conclusiones}

Más de tres de cada cuatro publicaciones vinculan la marca España con personas. Así, queda validada la primera hipótesis de la investigación: el vínculo establecido por la prensa entre la marca España y las personas es muy estrecho, dado que la mayor parte de los hechos noticiosos son protagonizados por determinadas personas o colectivos de personas.

Además, poco más de la mitad de las publicaciones que establecen un vínculo con determinadas personas muestran valoraciones positivas o neutras acerca de la influencia del hecho noticioso sobre la marca España. Este resultado refuta nuestra segunda hipótesis que apuntaba a que la valoración del impacto de los hechos noticiosos sobre la marca España era predominantemente negativa por el contexto sociopolítico adverso. Una parte de las valoraciones positivas se debe a la presencia de personas vinculadas a la cultura, dado que en lo referente a este ámbito "los hechos noticiosos vinculados a la marca España son predominantemente positivos debido al atractivo de la cultura como herramienta de influencia y soft power" (Carcavilla y Zugasti, 2019a, p. 290).

La persona que mayor protagonismo obtiene en la cobertura es el presidente del Gobierno, Mariano Rajoy, quien aparece en una de cada cuatro publicaciones. Le suceden el ministro de Asuntos Exteriores, José Manuel García-Margallo, promotor del proyecto Marca España, y el Rey Juan Carlos I, quien aparece en poco más de una de cada diez 
publicaciones. Además, en tres de cada diez publicaciones aparecen personas pertenecientes al ámbito de la cultura, de quienes una tercera parte son deportistas. Así, queda demostrada la tercera hipótesis: el Rey y el presidente del Gobierno tienen un protagonismo destacado en la cobertura como máximos representantes de la nación. Además, otras personalidades con prestigio internacional en los ámbitos del deporte y la cultura también tienen una presencia relevante (Anholt, 2009a; Peralba, 2010).

Cabe destacar la elevada vinculación existente entre la marca España y la clase política. En aproximadamente una de cada cuatro publicaciones aparecen otros miembros del Gobierno, y en una de cada cinco, otros políticos. Es asimismo reseñable la vinculación con empresarios concretos, quienes aparecen en una de cada cuatro publicaciones. Estos resultados ilustran la naturaleza política y empresarial de la marca España.

La vinculación del concepto 'marca España' con personas o grupos de personas es muy similar en la cobertura de los tres diarios analizados, siendo El Mundo el diario que registra mayor volumen de valoraciones positivas. El protagonismo de la Corona y los miembros de la Casa Real en El País y El Mundo es aproximadamente el doble que el registrado en La Vanguardia. Esto se plasma, por ejemplo, en las alusiones a la marca España en la cobertura de la abdicación de Juan Carlos I, cuya discreta presencia en el diario catalán contrasta con la obtenida en los diarios de Madrid.

En el ámbito deportivo, El Mundo y El País tienden a personalizar la marca España en los logros de los deportistas o equipos españoles, mientras que La Vanguardia no concede tanto protagonismo a deportistas concretos y muestra una mayor inclinación a establecer vínculos con asuntos que trascienden lo meramente deportivo. Además, la tendencia a vincular la marca España con personalidades de la cultura y el arte es mucho más pronunciada en El País. En concreto, es el diario que más vínculos establece con las áreas de literatura y teatro, cine, artes plásticas y arquitectura.

Estas conclusiones demuestran la cuarta hipótesis: los diarios analizados conceden diferente importancia a determinadas personas y hechos vinculados a la marca España y presentan peculiaridades al valorarlos.

Los resultados de este trabajo muestran el protagonismo concedido por la prensa a determinadas personas en relación con la marca España. Estos vínculos contribuyen a moldear el significado de este concepto entre la ciudadanía. A través del estudio del tratamiento periodístico de un caso concreto, esta investigación pretende aproximarse a la comprensión de un concepto complejo y difuso como es la marca país. Los resultados obtenidos pueden ampliarse y completarse con otras vías de investigación: ampliando la muestra cronológica y de medios, realizando un análisis cualitativo del discurso periodístico, estudiando la percepción de la ciudadanía sobre las figuras públicas que mejor representan la identidad nacional o analizando el tratamiento en la prensa internacional. 
El cambio de gobierno a mediados de 2018, tras la aprobación de una moción de censura contra Mariano Rajoy, puso fin a la figura del Alto Comisionado para la Marca España mediante la creación de la Secretaría de Estado de la España Global (Real Decreto 1266/2018, de 8 de octubre). Las líneas estratégicas adoptadas por España Global y su continuidad con el proyecto Marca España también abren opciones para ser objeto de estudio en futuras investigaciones.

\section{Bibliografía}

Aaker, D. (1996). Construir marcas poderosas. Barcelona: Gestión 2000.

Alcázar, M. (16 de noviembre de 2013). "Antonio Banderas: 'Yo sigo instalado en el respeto al Rey"'. La Vanguardia, p. 9.

Aldaz, C. (19 de febrero de 2014). “iQué desfile, Felipe!”. El Mundo, p. 45.

Andreu, J. (12 de julio de 2014). “Felipe VI, un rey 2.0”. El País, p.33.

Anholt, S. (2009a). "Branding places and nations". En Clifton, R. (ed.): Brands and Branding. Londres: Profile Books, pp. 206-216.

Anholt, S. (2009b). "Why National Image Matters". En WTO, Handbook on Tourism Destinations Branding. Madrid: WTO/ETC, pp. ix-xvi.

Azpíroz, M. L. (2012). Diplomacia pública: El caso de la 'guerra contra el terror'. Barcelona: Editorial UOC.

Berelson B. (1952). Content Analysis in Communication Research. Glencoe: Free Press.

Capriotti, P. (2009). Branding Corporativo. Fundamentos para la gestión estratégica de la Identidad Corporativa. Santiago de Chile: Business School Universidad Mayor.

Carcavilla, F. y Zugasti, R. (2019a). "El vínculo entre la marca España y la cultura en la prensa diaria". adComunica. Revista de Estrategias, Tendencias e Innovación en Comunicación, (18), 271-294. DOI: http://dx.doi.org/10.6035/21740992.2019.18.13

Carcavilla, F. y Zugasti, R. (2019b). "La vinculación periodística del concepto "marca España' con las empresas españolas”. Ámbitos. Revista Internacional de Comunicación, 43(1), pp. 70-94. DOI: 10.12795/Ambitos.2019.i43.04Casero, A. (2009). "El control político de la información periodística". RLCS, Revista Latina de Comunicación Social, 64, pp. 354-366. http://www.revistalatinacs.org/09/art/29_828_47_ULEPICC_08/Andreu_Casero .html DOI: 10.4185/RLCS-64-2009-828-354-366 
Cuatro (2018). "Santiago Segura desmonta a Torrente: 'Pensaba que era una cosa extinta y resulta que sigue estando muy vigente"." Disponible en: $<$ https://www.cuatro.com/chesterinlove/santiago-segura-entrevista-torrentebochorno_0_2517900306.html> [Acceso el 19 de octubre de 2019].

De Toro, J. M. (2009). La Marca y sus Circunstancias. Barcelona: Deusto.

Díaz Pérez, E. (23 de septiembre de 2015). "El psicodrama nacional”. El Mundo, p. 18.

El mejor deportista español en el peor momento de España (10 de junio de 2013). El Mundo, p. 3.

Foro de Marcas Renombradas Españolas (2019). "Embajadores Honorarios de la Marca España". Disponible en: <http://www.marcasrenombradas.com/marcaespana/ehme/> [Acceso el 25 de junio de 2019].

Guibernau, M. (2009). La identidad de las naciones. Barcelona: Ariel.

Junquera, N. (25 de octubre de 2012). "El Rey viaja a India para vender la marca España a 1.280 millones de consumidores". El País, p. 24.

Kerlinger, F. N. (1986). Foundations of behavioral research. Nueva York: Holt, Rinehart \& Winston.

La Porte, T. (2006). "La diplomacia cultural americana: una apuesta por el recurso al poder blando". Real Instituto Elcano, ARI nº 103.

Lippmann, W. (2007). Public Opinion. Minneapolis: Filiquarian Publishing.

Manfredi, J. L. (2011). "Hacia una teoría comunicativa de la diplomacia pública". Comunicación y Sociedad, vol. XXIV, 2, pp. 199-225.

Ministerio de Asuntos Exteriores y Cooperación (2016). "Marca España”. Disponible en: $<$ http://www.exteriores.gob.es/PORTAL/ES/POLITICAEXTERIORCOOPERA CION/MARCAESP/Paginas/Inicio.aspx> [Acceso el 22 de agosto de 2016].

Nye, J. S. (2004). Soft power: the means to success in world politics. Nueva York: Public Affairs.

OJD (2017). "Medios Controlados". Disponible en: <http://www.introl.es/medioscontrolados/> [Acceso el 8 de mayo de 2017].

Olins, W. (2005). "Making a National Brand". En Melissen, J. (ed.), The New Public Diplomacy: Soft Power in International Relations. Basingstoke: Palgrave Macmillan, pp. 169-179.

Peralba, R. (2010). El posicionamiento de la "Marca España” y su competitividad internacional. Madrid: Ediciones Pirámide.

Real Decreto 1266/2018, de 8 de octubre. BOE núm. 244, de 9 de octubre. 
Rodríguez Marcos, J. (25 de noviembre de 2014). "Sigue vigente el canon nacionalcatólico". El País, pp. 38-39.

Romero, A. (14 de abril de 2013). "La noche que el Rey se cayó en Botsuana”. El Mundo, pp. 6-7.

Sánchez Guitián, J. M. (2011). Marca País: España, una marca líquida. Madrid: Esic Editorial.

Sheinfeld, C. (2012). "Mi Casa es tu Casa'. Población local y diásporas en la Diplomacia Pública”. Retos de nuestra acción exterior: Diplomacia Pública y Marca España. Madrid: Colección Escuela Diplomática, n. ${ }^{\circ}$ 18, pp. 245-253.

Sierra Bravo, R. (1997). Técnicas de investigación social. Teoría y ejercicios. Madrid: Thomson.

Trueba, D. (3 de octubre de 2014). “Torrente vive". El País, p. 61.

Wilcox, D. L., y Cameron, G. T. (2006). Relaciones públicas. Estrategias y tácticas. Madrid: Pearson Educación.

Zurutuza, C. (2012). “Técnicas de investigación social en comunicación”. En Zugasti, R. (coord.): Investigar en ciencias sociales: el estudio de la comunicación. Zaragoza: Ediciones Universidad San Jorge, pp. 101-121.

\section{Notas}

[1] El poder blando o soft power se vincula con la capacidad de influencia de un país basada en el atractivo de su cultura y sus políticas y se contrapone al poder coercitivo o hard power, basado en la fuerza militar y económica (Nye, 2004).

[2] La publicity es un área de las relaciones públicas que tiende a confundirse con la publicidad. Se trata de información sobre un acontecimiento, un individuo, un grupo, o un producto que aparece como información en los medios de comunicación. A diferencia de la publicidad, que es un espacio pagado en un medio de comunicación, la publicity supone menores costes y es más creíble porque el mensaje aparece en el contexto de una noticia (Wilcox y Cameron, 2006: 21-22).

[3] Hemos considerado la dualidad del término, tanto en su referencia a la institución Marca España como en su sentido de identidad, imagen o reputación de España.

[4] Rafael Nadal fue nombrado Embajador Honorario de la Marca España en el año 2011 por iniciativa del Foro de Marcas Renombradas Españolas (Foro de Marcas Renombradas Españolas, 2019).

[5] Torrente es un personaje de ficción creado e interpretado por el actor, director, guionista y productor Santiago Segura. Su primera película, “Torrente, el brazo tonto de la ley” fue estrenada en España en 1998 y tras su rotundo éxito en taquilla, se rodaron cuatro secuelas. La saga se caracteriza por el humor zafio y vulgar de su protagonista, un policía fascista, machista, racista y alcohólico, un personaje esperpéntico que encarna una serie de estereotipos negativos asociados a una particular idea de España. En una entrevista en televisión, el propio Segura sentencia que "España sigue siendo Torrente y eso me abochorna" (Cuatro, 2018). 